\title{
Reflexões sobre os objetos e os ambientes físicos de ensino e pesquisa em saúde
}

\author{
Reflections about health \\ and educational objects and physical environments
}

Elio Grossman ${ }^{1}$

Tania Cremonini de Araújo-J orge ${ }^{1}$

Inesita Soares deAraujo ${ }^{2}$

\footnotetext{
${ }^{1}$ Setor delnovações

Educacionais, Laboratório de Biologia Celular, Instituto Oswaldo Cruz, Fundação Oswaldo Cruz. Avenida Brasil 4365, M anguinhos. 21045-900 Rio deJaneiro RJ. elio@fiocruz.br ${ }^{2}$ Instituto deComunicação elnformação Científicae Tecnológica, Fundação Oswaldo Cruz.
}

Abstract Thisarticlelooks to theobjectsand physical environments destined to teaching and re search in health from a different perspective. It addresses the communication between the designers and the people that use their projects and investigates in which ways the designer can contribute to a positive transformation of the state of mind of the users of teaching and health environments, taking into account the reaction of people to the products and environments, especially manifestations of pleasure and well-being. The article presents a pilot edition of an instrument for sensitization and data collection in form of a workshop called "Environment, Creation and Pleasure". Key words Health, Education, Design, Communication, Pleasure
Resumo 0 artigo traz um novo olhar sobre os objetos eambientes físicos destinados às atividades de ensino e pesquisa em saúde. Aponta questões sobrea comunicação entreos designers eas pessoas que utilizam seus projetos. Pergunta sobre as formas de contribuição do designer para a transformação positiva do estado de espírito dos usuários de ambientes destinados ao ensino e à saúde, levando em conta as reações ou sentimentos das pessoas peranteos produtos eosambientes, em especial manifestações deal egria ebem-estar. E apresenta a edição piloto de um instrumento diferenciado de sensibilização e levantamento de dados, no formato de oficina de trabal ho, denominada Espaço, Criação e Alegria.

Palavras-chave Saúde, Educação, D esign, Comunicação, Alegria 
Introdução

Vivemos num mundo coabitado por pessoas, animais, plantas, edificações e objetos, cuja convivência émarcada alternadamente pela sintonia e pela tensão. Longe de uma visão utópica de uma convivência perfeitamente harmoniosa entre essas entidades, buscamos um relacionamento que estimule o desejo, a curiosidade, a comunicação e o bom humor.

0 nosso olhar recai sobre o relacionamento entre as pessoas e os objetos que pode se dar nas casas, nos ambientes de trabalho, em escolas, em hospitais, nos espaços de lazer, de circulação urbana, entre outros. Tal relacionamento não é só da ordem funcional, mas também da ordem simbólica e pode despertar ou provocar sentimentos e emoções positivas ou negativas. No entanto, as reações humanas perante objetos e ambientes físicos ainda são pouco pensadas no planejamento e desenvolvimento de novos produtose novos espaços, ao contrário da literatura, do teatro ou do cinema, cujos autores escrevem um suspense, um drama ou uma comédia, cada qual intencionando provocar reações específicas.

Movidos por essa preocupação, perguntamos como os designers podem contribuir para a transformação positiva do estado de espírito dos usuários de ambientes destinados à saúde, visando à alegria e ao bem-estar dos pacientes e dos profissionais?

0 artigo aborda aspectos deidentificação das pessoas com os objetos e ambientes, em outras palavras, a comunicação entre designers e usuários na perspectiva da produção de sentidos sociais. Espera-se que esta comunicação gere reações positivas e de bom humor; desta forma, 0 texto busca, também, relacionar a alegria e o design. E, por fim, apresenta a experiência piloto da oficina de trabal ho, que configura a proposta de um método de sensibilização eescuta diferenciado para ser utilizado com usuários de ambientes físicos de ensino e pesquisa em saúde.

Cabe ressaltar que a práxis do design sob o ponto de vista da comunicação entre seus interlocutores, bem como as reações das pessoas perante produtos e ambientes físicos, não encontram uma única teoria que dê conta de explicáIos, o que nos leva a buscar referências em diversas áreas do conhecimento. 0 referencial teórico do nosso trabalho baseia-se em pesquisas ligadas à comunicação e à semiologia, no sentido de compreender a circulação e o consumo de sentidos na prática do design, além de estudos baseados na filosofia e na psicologia, para o entendi- mento das emoções e dos sentimentos humanos, em especial, manifestações de al egria como o riso.

Esclarecemos que o termo designer é utilizado no texto de acordo com a língua inglesa, que, deforma genérica, significa o profissional deprojeto, seja industrial ou de produto (industrial designer) ou de arquitetura (architectural designer ou architect). 0 designer aqui é visto como 0 profissional que planeja, concebe e desenvolve objetos e ambientes físicos, aprimorando as relações humanas com esses objetos e ambientes $e$ promovendo uma interação mais produtiva erica entre as pessoas e o meio construído.

Amor ou desamor à primeira vista no relacionamento com os objetos

Sabemos que o primeiro contato com um objeto é visual e mesmo antes de ser tocado esse objeto pode provocar reações favoráveis ou desfavoráveis que ocasionam aproximação ou rejeição do usuário. N esse primei ro contato visual, pode ser desencadeado um relacionamento deordem simbólica entre o usuário e o objeto ${ }^{1}$, possivelmente estimulando outros tipos de contato e estabelecendo a comunicação entre projetista e usuário; daí advém sua importância, sem deixar de se levar em conta a relevância dos demais tipos de interação. I nformações e estímulos visuais estão por toda parte. Se, por um lado, nas ruas e nos meios de comunicação, as pessoas estão sujeitas a uma grande variedade de informações, por outro lado, em certos ambientes de trabalho, de educação ou de serviços de saúde, encontra-se uma enorme monotonia. N esses espaços, é notável a carência de estímulos visuais bem formulados quegerem percepções positivas, proporcionando al egria e o bem-estar de todos.

Por outro lado, para obter informações sobre aspectos do relacionamento entre as pessoas e os objetos ou ambientes, visando a um determinado projeto, boa parte dos designers e arquitetos utiliza entrevistas superficiais, baseadas num tipo de comunicação de característica unidirecional que pressupõeum designer/transmissor num ponto e um usuário/receptor em outro ponto. No entanto, entendemos que a comunicação não é um simples ato de transferência de uma mensagem de um pólo a outro, mas o processo de produção dos sentidos (ou significados) sociais. Um processo que deve ser percebido em suas múltiplas fases, cuja interdependência é condição de existência: produção, circula- 
ção e apropriação (ou consumo). Em outros termos, os sentidos sociais, que possibilitam as práticas sociais, se formam por um processo que configura um "mercado", o mercado de bens simbólicos: opiniões, informações, crenças, saberes, percepções, olhares, enfoques teóricos, textos os mais diversos em conteúdo, formato e códigos de expressão são produzidos, entram em circulação e são "consumidos", tendo como resultante os sentidos sociais. Todas as pessoas que vivem em sociedade participam desse circuito, produzindo eatribuindo sentidosincessantemente, num processo contínuo deinterlocução. M esmo quando numa relação silenciosa com um determinado texto, uma pessoa pode ser vista como interlocutor, na medida em queatribui sentidos àquele texto, originalmente proposto por outra pessoa, também interlocutor ${ }^{2}$.

Objetos e ambientes podem ser percebidos como textos, por esse enfoque. Eles expressam um modo de perceber o mundo, a relação entre as pessoas e entre estas e os objetos. Objetos ( 0 produto do design) fazem circular sentidos. Portanto, podem ser considerados mediadores no processo de comunicação entre quem os projeta equem deles se apropria. Assim, falar dedesign é falar de comunicação, fazer design é estabelecer comunicação.

Barthes ${ }^{3}$, já nas suas primeiras leituras semiológicas, ressalta que pensamos viver os objetos como puros instrumentos, enquanto, na realidade, veiculam também sentidos queultrapassam e transbordam seu uso. No design, notamos que prevalece a visão de que o objeto "ideal" é o que possibilita ao usuário atribuir sentido semelhanteàqueleatribuído pelo designer, o quepermitiria uma interação satisfatória com esse objeto. No entanto, sempre existirão interpretações e usos inusitados e não planejados que devem ser percebidos e incorporados pelos designers.

Defato, é na interação com as pessoas que 0 sentido de um objeto é produzido. Por isto, 0 usuário deve se sentir convidado a explorar esse objeto ou jogar com ele até que tenha experimentado uma gama de sensações e manifestado reações eatribuído sentidos aos objetos. Deacordo com Krippendorff ${ }^{4}$, o sentido de um objeto não repousa na sua superfície, mas emerge na utilização, na vivência com o nosso ambienteem contextos particulares, sempre que nossas ações e percepções estejam cognitivamente conectadas num círculo experiencial deuso.

E ainda, considerando-se que o processo de comunicação estabelece um relacionamento entre os interlocutores, pode-se dizer que um co- nhecimento está sendo construído. Carvalho, Acioli eStotz ${ }^{5}$ afirmam que "a construção do conhecimento implica uma interação comunicacional, na qual os interlocutores com saberes diferentes, porém não hierarquizados, se relacionam a partir de interesses comuns". No nosso caso, os interlocutores são os designers e os usuários, já o interesse comum pode ser uma obra nova ou a reforma de um ambiente para a saúde.

\section{Como relacionar a al egria, o design ea saúde}

O bserva-se atual mente um movimento de valorização da al egria e do riso nos mais diferentes circuitos: no meio acadêmico, na mídia emesmo na medicina ${ }^{6}$. N uma sociedade assolada pelo medo, a partir das várias formas de violência, a al egria e o riso podem ser uma reação saudável e necessária à conquista e manutenção da qualidade de vida.

$\mathrm{Na}$ perspectiva da filosofia, como a alegria irrompe sem respeitar os desígnios da razão, fica clara sua ligação com a faculdade apetitiva da alma, isto é, das paixões, e não com a faculdade racional. A alegriae o riso revelam o queé "excluído pela ordem, o desvio e o indizível, e tem a faculdade de nos fazer apreender a realidade que a razão séria não alcança"6. Para Espinosa, citado por Chauí 7 , somos seres naturalmente passionais, porque sofremos a ação de causas exteriores a nós. Segundo ele, "as paixões não são boas nem más: são naturais. Três são as pai xões originais: alegria, tristeza e desejo"7. As demais derivam-se destas; assim, da alegria nascem o amor, a esperança, a segurança, o contentamento; da tristeza, surgem o ódio, a inveja, o orgulho, 0 medo; do desejo, provém a gratidão, a ambição, a ousadia. E o filósofo holandês conclui que "uma pai xão triste é aquela que diminui nossa capacidade de ser e agir; ao contrário, uma paixão alegre aumenta a capacidade de existir eagir de nosso corpo e de nossa alma"7.

A alegria e o riso podem advir de situações inesperadas, súbitas, desconhecidas, que geram surpresa e admiração. Segundo Alberti ${ }^{6}$, "rimos quando esperamos um determinado desfecho, e o que ocorreéuma quebra dessa expectativa". As coisas que geralmente nos trazem al egria e nos levam a rir devem ser dotadas de certa novidade e devem aparecer diante de nós de maneira imprevista. Para Quentin 8 , "o inesperado gera admiração, a admiração gera alegria e é a al egria quenosfaz rir".

Sobre a relação entre o riso e o pensamento, 
Alberti ${ }^{9}$ cita vários filósofos que tentaram desvendar os segredos do riso e que, na verdade, acabaram apresentando-o mais como um elemento revelador. Ritter, em Alberti ${ }^{9}$, afirma que a al egria e o riso estão ligados aos caminhos seguidos pelo homem para encontrar e explicar o mundo: "eles têm a faculdade de nos fazer reconhecer, ver e apreender a realidade que a razão séria não atinge". Para Bataille, também em Alberti ${ }^{9}$, o riso se mostrou "a questão chave, a reve lação, [...] o que abria o fundo das coisas"; acrescentando, ele nos diz: "eu não imaginava que rir me dispensasse de pensar, mas que rir melevaria mais longe do que o pensamento". Já Nietzsche ${ }^{10}$ é taxativo: "e que seja tido por nós como falsa toda a verdade que não acolheu nenhuma gargaIhada". E N ietzsche ${ }^{10}$ nos ensina que "quanto mais seguro, mais o homem desprende a gargalhada - que é necessária para sair da verdade séria, da crença na razão e da positividade da existência".

Outro aspecto relevante é que o riso como manifestação de alegria, segundo $M$ enezes $^{11}$, é "essencialmente comunicativo [...] ederiva desituações de aproximação e identidade". Complementando este pensamento, o filósofo Espinosa assinala que "o Bem Verdadeiro é aquele capaz decomunicar-se a todose ser compartilhado por todos"7.

Sob o ponto de vista da psicologia, Freud ${ }^{12}$ estudou o riso na sua obra Os chistes e sua relação com o inconsciente. Segundo ele, a origem do prazer no chiste é o jogo com as palavras e os pensamentos na infância, que cessa tão logo a crítica ou a razão declaram sua ausência de sentido. 0 jogo de palavras, por seu lado, causa prazer porque nos dispensa do esforço necessário à utilização séria das palavras. "O humor tem não apenas al go de libertador", observa Freud"2, "mas também algo de sublime e elevado".

No que se refere ao design, se por um lado, os objetos da era moderna nos proporcionam formas leves, despojadas e muito bem proporcionadas, por outro, o racionalismo e a padronização excessivas, presentes nestes objetos, levam a uma certa monotonia com a utilização de materiais e acabamentos muito homogêneos. 0 homem moderno, muito comumente, ao manifestar afinidade com um novo objeto de design ou de arte, privilegia a observação "inteligente" e procura encontrar um sentido racional para o que vê. 0 objeto começa, a partir daí, a dialogar com a razão e não mais com as emoções.

Os grupos de palhaços D outores da A legria ${ }^{13}$ e Doutores do Riso ${ }^{14}$, cujo objetivo principal é atenuar, por meio da alegria, o sofrimento de crianças internadas ao quebrar a rotina e mudar a atmosfera de um hospital frio e atemporal, são bons exemplos de ações que relacionam a al egria e a saúde. Pensamento semelhante pode ser utilizado no projeto dos móveis, utensílios, paredese equipamentos médico-hospitalares que coabitam com os pacientes e profissionais nos ambientes hospitalares, ambulatoriais, laboratoriais e de ensino em saúde.

Existem, também, vários exemplos de produtos, alguns lançados na década de 1960 , sob a influência do movimento pop e outros na década de 1970 estimulados pel os conceitos pós-modernistas que podem nos dar pistas para atributos de projeto que proporcionem reações de al egria. São produtos bem humorados, super coloridos e quevisam a atender a uma necessidadefuncional, mas antes disso promover a aproximação por meio da simpatia, estimulando o bom humor do observador ou do consumidor. Tais produtos, ao contrário dos objetos inanimados e da assepsia funcional, se transformam em pequenos seres engraçados ou em cenas bem humoradas e foram concebidos por importantes designers que consideramospós-funcionalistas, como osirmãos Castiglioni, Verner Panton, Aldo Rossi, Richard Sapper, Javier Mariscal, Michele de Lucchi, M ichael Graves, PhilippeStarck eoutros ${ }^{15,16}$. N o Brasil, podemos citar Flávio de Carvalho, Aurélio M artinez Flores, Luciano Deviá, Guto Lacaz e os irmãos Campana, dentre outros.

Os caminhos apontados por esses importantes designers são estímulos para que se busque um ferramental teórico que dê suporte ao designer para trabalhar de forma intencional na direção do bom humor daqueles que utilizam seus projetos. N esse sentido, o design poderá proporcionar uma melhor qualidade de relacionamento entre as pessoas e os objetos e ambientes, promovendo uma interação mais rica e prazerosa entre as pessoas e o seu meio, povoado de equipamentos, móveis, computadores, utensílios, luminárias, maçanetas, portas, janelas, torneiras, enfim, toda a sorte de produtos com os quais convivemos cotidianamente.

\section{Que instrumento utilizar} para uma escuta sensível

As emoções talvez sejam porções das mais complexas, subjetivas e fascinantes da psique humana. Os questionários ou as entrevistas tradicionais nem sempre se mostram adequados para levantar aspectos referentes a emoções e senti- 
mentos provocados por elementos físicos sobre os quais as pessoas não estão habituadas a opinar ou, de uma forma geral, não têm voz. Para tanto, é necessário um instrumento que sensibilize os partici pantes, trabal he a afetividade epossibilite reflexões sobre o tema para que eles possam se manifestar de uma forma mais envolvida com as suas experiências, com as suas emoções, com as experiências e as emoções dos demais e com o meio.

Objetivando aprimorar o diálogo entre quem projeta e quem utiliza objetos e ambientes, propomos um método diferenciado de expressão e registro de percepções, opiniões e demandas dos usuários de ambientes de saúde. Tal método inclui formas de sensibilização e reflexão para se alcançar manifestações de ordem objetiva e subjetiva. A proposta é trabalhar novos pensamentos e possi bilidades de transformação do espaço físico, com exercícios práticos e reflexões sobre aspectos de identificação com o ambiente e com os objetos, localização no espaço, formas de re presentação, funções e usos dos objetos. A oficina se configura, portanto, como um método proposto de escuta pré ou pós intervenções físicas em espaços físicos destinados à atividades de saúde. N esse sentido, estruturamos a oficina de trabalho denominada Espaço, Criação e Alegria.

A oficina foi testada numa edição piloto em abril de 2005, com um público de educadores que participaram da disciplina Ciência eArte, do programa de pós-graduação em Ensino de Biociências e Saúde da Fiocruz, e al guns professores da rede pública de ensino. Esse primeiro testepermitiu verificar a eficácia de uma vivência tanto como elemento sensibilizador de pessoas envolvidas com uma questão, como também um instrumento de escuta sensível da realidade de cada participante numa forma coletiva e colaborativa.

A oficina é concebida para atividade durante três horas sucessivas, é conduzida por um mediador, apoiada por um monitor e pode contar com a participação de até quinze pessoas. Sua documentação se dá através da coleta dos desenhos produzidos, por meio do registro fotográfico e dos depoimentos gravados dos participantes, com a devida autorização de cada um deles. Ela é estruturada com os seguintes exercícios:

Prática 1.0 primeiro contato com o ambiente: simpatia ou antipatia.

A pós uma breve introdução sobre o objetivo da oficina e a apresentação de todos os participantes, o mediador propõe a primeira atividade individual:

- Fale um objeto que você gosta e um objeto que você não gosta. Os objetos citados são registrados por meio de anotações feitas pelo mediador e ao final todos tecem comentários sobre a sua própria escolha e sobre a escolha dos demais, estabelecendo naturalmente ligações entre os objetos escolhidos, seus ambientes etraços da personalidade de cada um. Esta, também, éuma forma de apresentação e um aquecimento para as demais práticas.

Prática 2. Localização espacial: dimensões do espaço.

O mediador apresenta os conceitos gerais de espaço (geográfico, social e pessoal), falando da importância da local ização no espaço e exibindo imagens que vão da Terra vista do espaço, passando pela América do Sul, pelo Brasil, pela cidade do Rio de Janeiro até chegar ao prédio ea sala que abriga a oficina. N essas imagens, são destacadas suas formas de representação, que podem ser desenhos, plantas, mapas e maquetes e seus elementos, como cores e formas.

Segue-se a segunda atividade individual na qual o mediador propõe que façam a planta baixa ou a perspectiva humanizada (com objetos, móveis, etc.) da sua sala de aula ou da sala de casa ou do seu quarto ou do seu ambiente de trabalho (Figuras 1, 2, 3, 4 e 5).

Por meio do desenho, é possível o indivíduo transmitir a sua experiência eo queéimportante para ele, como pensa, como sente e como vê. Os estudos da representação gráfica por parte de adultos ocorrem basicamenterelacionados à formação e à prática profissional de designers, arquitetos e artistas plásticos; por esse motivo, a

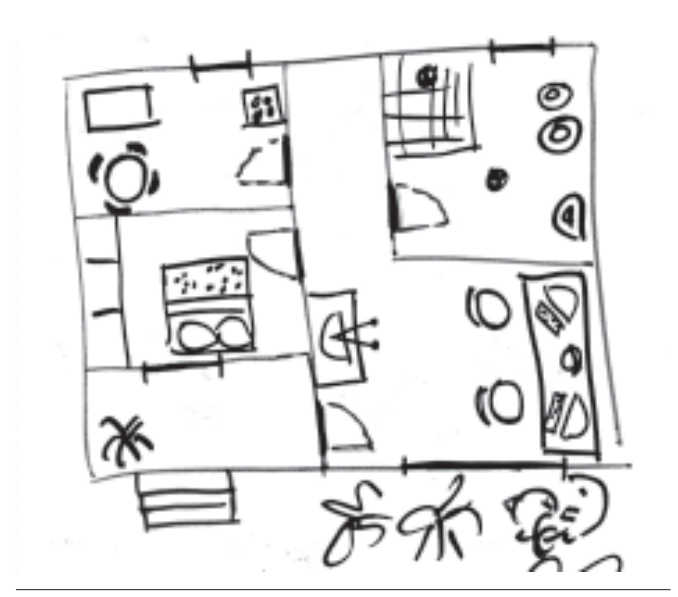

Figura 1. Ambiente de casa. 


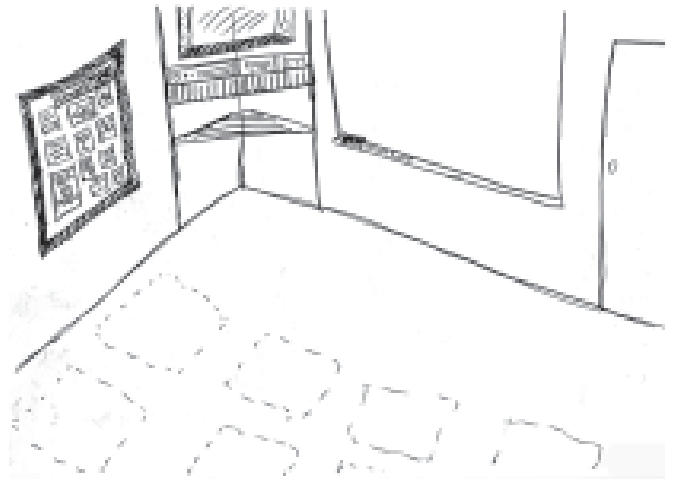

Figura 2. Ambiente de trabalho.
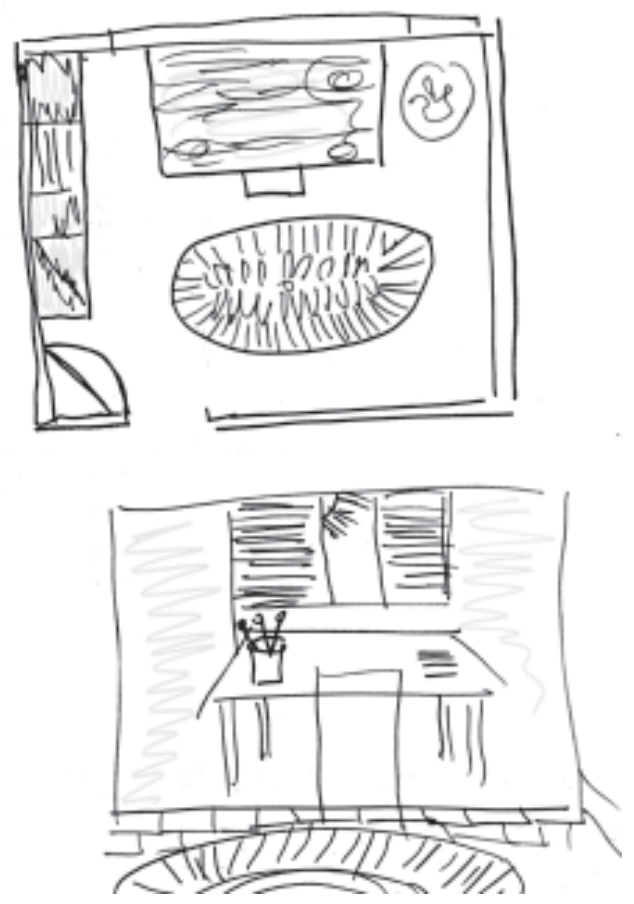

Figura 3. Ambiente de casa.

leitura dos desenhos produzidos por sujeitos não desenhistas durante a oficina se baseou na adaptação dos estudos de Piaget e Inhelder ${ }^{17}$ sobre a representação do espaço pela criança e $M$ èredieu ${ }^{18}$ sobre o desenho infantil, em particular os aspectos do desenho voluntário que acontece a partir do momento em que se estabelece uma analogia entre os traçados do desenho e um objeto real, numa abordagem não só cognitiva, mas também afetiva do desenho.

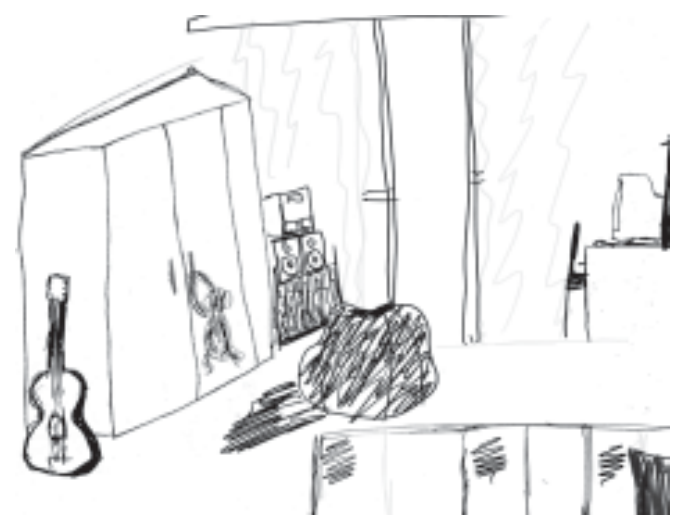

Figura 4. Ambiente de casa.

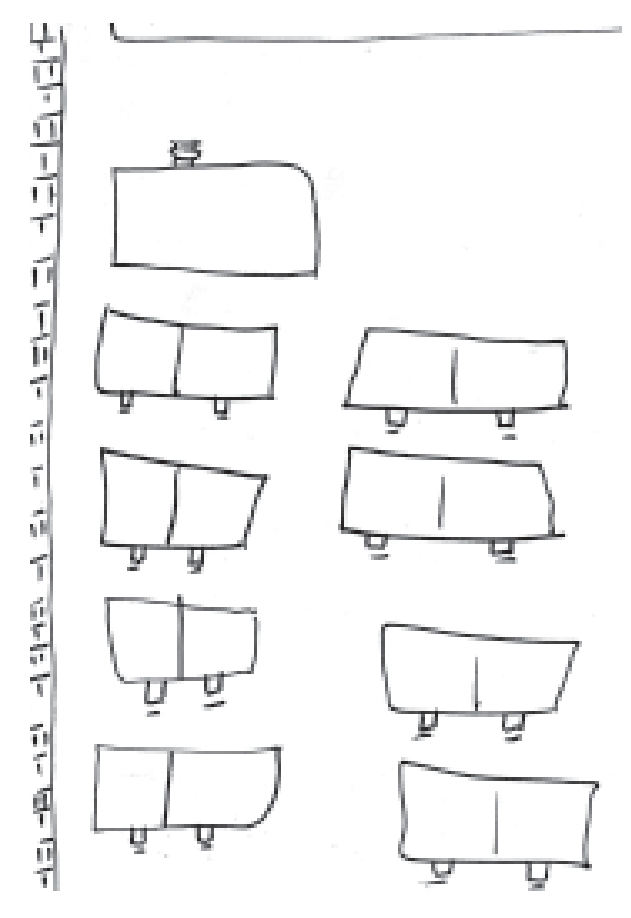

Figura 5. Ambiente de trabalho.

Nos desenhos colhidos na primeira edição da oficina (Figuras 1, 2, 3, 4 e 5), podemos perceber importantes aspectos do relacionamento dosparticipantes com o ambiente retratado, sobre os quais tecemos alguns comentários. Perante a possibilidade de escolha entre desenhar ambientes domésticos ou detrabalho, a maioria dos participantes opta em desenhar um ambiente da sua casa (Figuras 1, 3, 4); de certa forma, essa preferência demonstrauma maior identificação com 0 
ambientedoméstico, cujos desenhos exibem uma maior quantidade de objetos, os quais, provavelmente, refletem uma afetividade com os mesmos e estão representando as pessoas a que eles pertencem. As formas de representação em planta baixa (Figuras 1 e 5) e por meio do desenho em perspectiva (Figuras 2 e 4) são em quantidades equivalentes e somente um desenho usa as duas representações (Figura 3). De uma forma geral, as representações em planta baixa revelam a necessidade de exibir o ambiente completo, porém de uma forma distanciada ou esquemática; já os desenhos em perspectiva demonstram um determinado ponto de vista e de uma maneira mais aproximada. A maior parte dos desenhos emprega várias cores (Figuras 1, 3, 4), denotando alegria e riqueza de detalhes, sendo que os únicos desenhos monocromáticos representam ambientes de trabalho (Figuras 2 e 5 ), provavelmente simbolizando aspectos de monotonia.

Sobre a representação do espaço por meio do desenho, $M$ èredieu ${ }^{18}$ nos diz que não existe espaço em si, mas uma pluralidade de espaços possíveis, eo aparecimento de cada um depende estreitamente das condições socio-históricas do momento, como também da história pessoal de cada um que vive determinado espaço.

Prática 3. Funções e usos dos objetos: outros usos dos objetos.

0 mediador discorre sobre a tipologia dos objetos, citando e mostrando exemplos: utilitários- os que nos auxiliam; ferramentas - aqueles que transformam; móveis - os que suportam pessoas e objetos; artísticos - aqueles que embelezam. A partir daí, é colocada a primeira atividade de grupo:

- Proponham um novo uso para as cadeiras da sala. Os participantes aproveitam a oportunidade e propõem outras possibilidades de uso para as cadeiras, resultando em uma escultura e outros tipos de móveis como uma mesa e uma cama. Dessa forma, vivem a experiência deir além da função original de um objeto ao propor novas utilizações e arranjos para eles.

No final do trabalho, faz-se uma avaliação geral para que cada participante relate sua percepção sobre a vivência na oficina e fale sobre as possibilidades dele interferir no espaço físico. A seguir, alguns depoimentos bastante significativos, que foram colhidos na oficina piloto durante a avaliação:

$\mathrm{N}$ ão tenho jeito para desenho, mas estou gostando muito de me expressar assim.

N unca tinha feito uma planta baixa, isso ajuda a pensar o espaço.
$N$ ão conseguia imaginar que poderia mudar as coisas de lugar e mudar as cores eque isso muda 0 ambiente e muda as pessoas.

Agora acredito que posso mudar as carteiras da minha sala de aula eisso vai ajudar a melhorar o meu relacionamento com os alunos.

Esse grupo de práticas nos pareceu suficiente para a oficina piloto; pensando na realização da oficina em laboratórios de pesquisa em saúde, onde pretendemos focar nossa pesquisa, propomos uma quarta prática, para ajudar a trazer notícias mais específicas do relacionamento dos participantes com essetipo de ambiente. São perguntas que cada partici pante responde de forma individual perante o grupo, para depois todos fazerem uma reflexão coletiva. 0 roteiro dequestões sobre o espaço de trabalho que elaboramos para a Prática 4 é o seguinte:

1) $O$ que você costuma fazer aqui?

2) 0 que você gosta nesse espaço?

3) 0 que você não gosta nesse espaço?

4) $O$ que você gostaria que tivesse nesse ambiente?

5) 0 que você acha do tamanho desse ambiente? aqui?

6) 0 que vocêacha da quantidade de objetos

7) 0 quevocêacha das cores desse ambiente? Qual delas você melhor percebe?

8) 0 que você acha da iluminação daqui?

9) 0 quevocêacha da temperatura desta sala?

10) O que vocêacha dos móveis quevocêutiliza aqui? São adequados para suas necessidades, como sentar, apoiar, escrever, guardar, acessar?

11) 0 que vocêgostaria de fazer aqui enão é possível?

12) 0 ambiente físico favorece as atividades aqui desenvolvidas por você?

13) Você acha que esse ambiente facilita ou favorece o relacionamento entre as pessoas?

14) Alguma coisa nesse ambiente Ihe entristece?

15) Você acha al guma coisa engraçada neste ambiente? Algo aqui Ihe faz sorrir?

16) Vocêteve alguma partici pação na escolha dos elementos que compõem o ambiente?

\section{Conclusões}

Primeiramente, no que diz respeito à comunicação entre designers e usuários, devemos ficar atentos para não nos referenciarmos no olhar dominante baseado no modelo emissor-receptor, o qual secaracteriza por ser linear, unidirecio- 
nal e bipolar. Podemos construir outras possibilidades de comunicação a partir de novos olhares baseados na interlocução que pressupõe uma circularidadedesentidos. Dessa forma, podemos compreender melhor e operar o mercado simbólico de produção, circulação econsumo desentidos em design e arquitetura.

Ficaclaro, também, queaalegria podeimpregnar todo o tipo de atividade humana. Podemos dar um passo além da funcionalidade e associar a alegria ao design e à arquitetura, abrindo assim um caminho interessante para transformar os ambientesfísicos desaúdee deensino em ambientes promotores de saúde. 0 ambiente físico, desta forma, passa a ter sua relevância equiparada a tudo aquilo, sejam procedimentosou equipamentos, que énecessário para o bom desenvolvimento das atividades realizadas nestes ambientes.

$\mathrm{Na}$ oficina de trabal ho piloto, o resultado de cada exercício e a expressão de cada participante nos desenhos, nas dramatizações e nas falas nos indica a riqueza de informações que esse instrumento podenos trazer. A linguagem do desenho, em particular, se mostrou um excelente meio de expressão e comunicação da memória afetiva e da percepção de cada participante sobre o meio queo circunda. A oficina, ao trabal har fatores de percepção, de localização edas representações do espaço, amplia o repertório dos participantes e os ferramenta para lidar com situações de intervenções no espaço físico. A experiência da oficina piloto nos dá fortes indícios de que ouvir e levar em conta as opiniões dos usuários, por meio de um instrumento de escuta sensível, pode ser determinante no desenvolvimento de projetos de ambientes físicos bem formulados e impregnados de estímulos positivos.

A discussão em torno de ambientes físicos promotores da saúde merece ser ampliada com o intuito de fornecer subsídios para a construção de melhores políticas públicas em infra-estrutura em ensino e saúde, pensando em projetos de obras ou reformas de unidades de pacientes internos, em unidades ambulatoriais, em laboratórios de pesquisa em saúde e em ambientes educacionais. Desta forma, imaginamos a saúde e a educação com ambientes menos frios e monótonos e mais estimulantes e saudáveis, nos quais seja possível observar reações de alegria e bem-estar.

\section{Colaboradores}

E Grossman participou da formulação da pesquisa, da concepção da oficina de trabalho e da produção do artigo. TC Araújo-Jorge e IS Araujo participaram da formulação da pesquisa e da produção do artigo. 


\section{Referências}

1. Baudrillard J. 0 sistema dos objetos. São Paulo: Perspectiva; 1973.

2. Araújo IS. Mercado simbólico: um modelo de comunicação para políticas públicas. Interface - Comunic., Saúde, Educ. 2003; 8(14):165-177.

3. Barthes R. Semântica do objeto. In: Barthes R. A aventura semiológica. São Paulo: M artins Fontes; 2001.

4. Krippendorff K. Product Semantics: a triangulation and four design theories. In: Product Semantics '89 Conference; 1989 M ay 12; Helsinki: Seppo Vak; 1990; p. a.3-23.

5. Carvalho MAP, Acioli S, Stotz EN. O processo de construção compartilhada do conhecimento: uma experiência de investigação científica do ponto de vista popular. In: Vasconcelos EM, organizador. A saúde nas palavras e nos gestos: reflexões da Rede de Educação Popular e Saúde. Volume 1. 1a ed. São Paulo: Hucitec; 2001. p. 101-114.

6. Alberti V. 0 pensamento e o riso: a transformação do riso em conceito filosófico. Rio de Janeiro: CPDOC; 2000.

7. Chauí M. Convite à Filosofia. São Paulo: Ática; 2003.

8. Quentin S. A arma do riso. Folha de São Paulo 2002; 8 abr.

9. Alberti V. 0 riso e o risível na história do pensamento. Rio de Janeiro: Jorge Zahar; 1999.

10. Nietzsche F. A Gaia Ciência. Rio de Janeiro: Ediouro; 1998.
11. M enezes EDB. O riso, o cômico e o lúdico. Revista de Cultura Vozes 1974; 1:5-16

12. Freud S. Os chistes e sua relação com o inconsciente. Rio de Janeiro: Imago; 1977.

13. Doutores da Alegria. O que é o Centro de Pesquisa e Desenvolvimento dos Doutores da Alegria [site na Internet]. [acessado 2005 ago 17]; 1(1): [cerca de 3 p.]. Disponível em: http://www.doutores daalegria.org.br/internas.asp? secao=centrode estudos_apresentacao

14. Doutores do Riso. Nosso trabalho [site na Internet]. [acessado 2005 ago 17]. Disponível em: http:/ /www.doutoresdoriso.com.br/home/nossostrabalho.asp

15. Fiell C, Fiell P. 1000 chairs. Köln: Taschen; 2000.

16. Sparke P, Hodges F, Coad E. Design Sourcebook. New Jersey: Chartwell; 1993.

17. Piaget J, Inhelder B. A representação do espaço na criança. Porto Alegre: Artes M édicas; 1993.

18. M èredieu F. O desenho infantil. São Paulo: Cultrix; 1993.

Aprovado em 13/06/2007

Versão final apresentada em 26//09/2007 